\title{
Endogenous Activation of Serotonin-2A Receptors Is Required for Respiratory Rhythm Generation In Vitro
}

\author{
Fernando Peña and Jan-Marino Ramirez \\ Committee on Computational Neurobiology, Committee on Neurobiology, and Department of Organismal Biology and \\ Anatomy, University of Chicago, Chicago, Illinois 60637
}

Endogenous amines and peptides continuously modulate the activity of neuronal networks and are required even for their normal operation. The respiratory rhythm generator, localized in the pre-Bötzinger complex, is not an exception. This network is modulated by various neurotransmitters, including serotonin (5-HT). In this study, we isolated the respiratory network in brainstem slices and demonstrate that the endogenous activation of $5-\mathrm{HT}_{2 \mathrm{~A}}$ is required for the generation of the respiratory rhythm in vitro. At the network level, activation of $5-\mathrm{HT}_{2 \mathrm{~A}}$ receptors with 4-iodo-2,5-dimethoxyamphetamine or the 5-HT uptake blocker alaproclate increased the frequency of respiratory activity. Blockade of endogenously activated $5-\mathrm{HT}_{2 \mathrm{~A}}$ receptors with three different antagonists decreased the frequency, amplitude, and regularity of respiratory population activity, an effect that was blocked by protein kinase $C$ (PKC) activators. At the cellular level, blockade of $5-\mathrm{HT}_{2 \mathrm{~A}}$ receptors reduced the action potential discharge in all examined respira- tory neurons, which was associated with a reduction in the fast and the persistent sodium current. Continuous application of 5- $\mathrm{HT}_{2 \mathrm{~A}}$-receptor antagonists differentially affected pacemaker neurons. Pacemaker activity was eliminated in cadmiuminsensitive pacemaker neurons. In cadmium-sensitive pacemaker neurons, the frequency of pacemaker activity was unaffected and the amplitude of pacemaker bursts was enhanced. It is assumed that cadmium-insensitive pacemakers rely on the persistent sodium current, whereas cadmium-sensitive pacemakers depend on the activation of calcium currents. We conclude that endogenously activated $5-\mathrm{HT}_{2 \mathrm{~A}}$ receptors are required for maintaining fictive respiratory activity in the brainstem slice by modulating sodium conductances via a PKC pathway.

Key words: respiratory rhythm; endogenous serotonin; pre-Bötzinger complex; 5- $\mathrm{HT}_{2 \mathrm{~A}}$ receptor; pacemaker; sodium currents
Neuronal networks are modulated continuously by endogenously released amines and peptides. For invertebrate neuronal networks, such as the stomatogastric system of the crustacean, it has been demonstrated that neuromodulators are required for normal operation. In these networks, membrane properties are tuned in such a way that endogenous modulators are necessary to bring them into a functional voltage range (for review, see Nusbaum and Beenhakker, 2002). The concept that endogenously released neuromodulators are required for the operation of a neuronal network also applies to mammalian nervous systems. For example, it has been shown that substance $\mathrm{P}$ plays a major role modulating the activity of the respiratory network both in vivo (Gray et al., 2001) and in vitro (Telgkamp et al., 2002). Several studies suggest that endogenous serotonin (5-HT) is required during the maturation of the neuronal network that controls breathing (Di Pasquale et al., 1994; Bou-Flores et al., 2000).

Increasing evidence indicates that the breathing rhythm is generated by a neuronal network located within the preBötzinger complex (PBC) in the medulla (Smith et al., 1991). Isolation of the $\mathrm{PBC}$ in transverse slices in vitro preserves rhyth-

\footnotetext{
Received Aug. 23, 2002; revised Oct. 4, 2002; accepted Oct. 9, 2002.

This work was supported by a Pew Charitable Trust Fellowship (F.P.) and by grants from the Rett Syndrome Research Foundation and the National Institutes of Health. We thank Dr. Marjorie Parkis for her insightful comments on this manuscript.

Correspondence should be addressed to Jan-Marino Ramirez, Department of Organismal Biology and Anatomy, Committee on Neurobiology, University of Chicago, 1027 East 57th Street, Chicago, IL 60637. E-mail: Jramire@midway. uchicago.edu.
}

Copyright (C) 2002 Society for Neuroscience $0270-6474 / 02 / 2211055-10 \$ 15.00 / 0$ mic activity (Smith et al., 1991), which is characterized by different activity patterns. Quantitative measurements of the frequency, amplitude, and shape of this rhythmic activity led to the discrimination of three very distinct activity patterns that are generated under normoxic and hypoxic conditions (Lieske et al., 2000). In this study, we present data indicating that endogenously released 5-HT acting on the 5- $\mathrm{HT}_{2 \mathrm{~A}}$ receptor is required for the operation of the respiratory network isolated in transverse slices of neonatal mice.

Exogenously applied 5-HT exerts complex modulatory effects on respiration (Morin et al., 1990, 1991; Lalley et al., 1994, 1995; Rose et al., 1995), particularly in in vivo preparations (Bianchi et al., 1995; Haji et al., 2000). This is attributable to the presence of multiple 5-HT-receptor subtypes (Barnes and Sharp, 1999) that cause diverse respiratory effects at the single-neuron and network level (Bohmer et al., 1979; Champagnat et al., 1979; Arita and Ochiishi, 1991; Lalley et al., 1997). Because of this complexity, we examined the endogenous role of only one receptor subtype, the $5-\mathrm{HT}_{2 \mathrm{~A}}$ receptor. Exogenous applications of specific 5- $\mathrm{HT}_{2 \mathrm{~A}}$ agonists are known to exert an excitatory effect on respiratory activity in vitro (Onimaru et al., 1998) in anesthetized cats (Lalley et al., 1995) and in conscious rats (Cayetanot et al., 2002). This effect can be mimicked in transverse slices (Al-Zubaidy et al., 1996) by stimulating raphe neurons, the primary source of endogenous 5-HT. Because 5-HT-containing neurons fire tonically (Richerson et al., 2001), continuously released 5-HT acting on the $5-\mathrm{HT}_{2 \mathrm{~A}}$ receptor can modulate the respiratory network. The data presented in this study suggest that endogenously released 5-HT acting on the $5-\mathrm{HT}_{2 \mathrm{~A}}$ receptor modulates the transient and the 
persistent sodium current in PBC neurons. This is particularly interesting because the activation of the persistent sodium current in respiratory neurons has been implicated in the generation of the respiratory rhythm (Butera et al., 1999; Smith et al., 2000).

\section{MATERIALS AND METHODS}

Preparation. Experiments were performed on brainstem transverse slices from male and female CD1 mice [postnatal day 1 (P1)-P13] using a preparation technique described in detail previously (Ramirez et al., 1996). The most important steps are summarized here. The experimental procedures were approved by the Institutional Animal Care and Use Committee at the University of Chicago. Animals were deeply anesthetized with ether delivered by inhalation and decapitated, and the isolated brainstem was placed in an ice-cold artificial CSF (aCSF) bubbled with carbogen $\left(95 \% \mathrm{O}_{2}\right.$ and $\left.5 \% \mathrm{CO}_{2}\right)$. The aCSF contained (in $\left.\mathrm{mm}\right): 128$ $\mathrm{NaCl}, 3 \mathrm{KCl}, 1.5 \mathrm{CaCl}_{2}, 1 \mathrm{MgSO}_{4}, 24 \mathrm{NaHCO}_{3}, 0.5 \mathrm{NaH}_{2} \mathrm{PO}_{4}$, and 30 D-glucose, $\mathrm{pH}$ 7.4. The brainstem, glued with the rostral end up onto an agar block, was mounted into a vibratome and serially sliced from rostral to caudal until the rostral boundary of the PBC was identified by specific landmarks such as the inferior olive, the nucleus ambiguus, and the hypoglossal nucleus (XII) (see Fig. $1 A$ ). Slices (500- to 700- $\mu$ m-thick) containing the $\mathrm{PBC}$ were transferred into a recording chamber, continuously perfused with oxygenated $\mathrm{aCSF}$, and maintained at $29^{\circ} \mathrm{C}$. To obtain and maintain consistently fictive respiratory rhythmic activity, the potassium concentration of the perfusing aCSF was raised from 3 to 8 mM over $30 \mathrm{~min}$. Under these conditions, respiratory rhythmic activity was stable for many hours.

Recordings. Population activity recordings were obtained with suction electrodes positioned on the surface of the PBC. The signals were amplified 2000 times, filtered (low-pass, $1.5 \mathrm{kHz}$; high-pass, $250 \mathrm{~Hz}$ ), rectified, and integrated using an electronic filter (time constant, 30-50 $\mathrm{msec}$ ). Integrated population activity from the $\mathrm{PBC}$ was in phase with integrated XII activity (Telgkamp and Ramirez, 1999; Thoby-Brisson et al., 2000). Therefore, extracellularly recorded PBC activity was used as a marker for inspiratory population activity (see Fig. 1).

Whole-cell patch-clamp recordings were obtained from PBC neurons using two different techniques: the blind-patch and the patch-clamp technique under visual control. Respiratory neurons were identified according to their anatomical location and their discharge characteristics with respect to the population respiratory activity (see Fig. 1A). The discharge pattern of each cell type was identified first in the cell-attached mode. Experiments were then performed in the whole-cell patch-clamp mode. The respiratory neurons were current-clamped at the zero-current potential. The patch electrodes were manufactured from filamented borosilicate glass tubes (G150F-4; Warner Instruments, Hamden, CT). Blind-patch electrodes used for current-clamp recordings were filled with a solution containing (in $\mathrm{mM}$ ): $140 \mathrm{~K}$-gluconic acid, $1 \mathrm{CaCl}_{2} \cdot 6 \mathrm{H}_{2} \mathrm{O}, 10$ EGTA, $2 \mathrm{MgCl}_{2} \cdot 6 \mathrm{H}_{2} \mathrm{O}, 4 \mathrm{Na}_{2} \mathrm{ATP}$, and $10 \mathrm{HEPES}$. The K-gluconic acid-containing electrode solution resulted in a significant liquid junctional potential ( $\mathrm{LJP} ; \sim 12 \mathrm{mV}$ ), which affected the measured membrane potentials. All membrane potential values were corrected for this LJP as described by Neher (1992). Input resistance was determined according to the voltage change in response to the injection of hyperpolarizing DC pulses. Patch-clamp electrodes used for voltage-clamp recordings to isolate $\mathrm{Na}^{+}$currents were filled with a solution containing (in mM): 110 $\mathrm{CsCl}, 30$ tetraethylammonium chloride, $1 \mathrm{CaCl}_{2}, 10$ EGTA, $2 \mathrm{MgCl}_{2}, 4$ $\mathrm{Na}_{2} \mathrm{ATP}$, and 10 HEPES, $\mathrm{pH}$ 7.2. This pipette solution resulted in a small LJP $(<3 \mathrm{mV})$, which was not corrected in this study. Neurons were held at $-60 \mathrm{mV}$, and after identification of the type of respiratory neurons, $200 \mu \mathrm{M} \mathrm{CdCl}{ }_{2}$ was added to the bath to block $\mathrm{Ca}^{2+}$ currents (Elsen and Ramirez, 1998).

All recordings were stored on a personal computer using Axotape (version 2.0) or pClamp 6 (Axon Instruments, Foster City, CA) and analyzed off-line using customized analysis software written with IGOR Pro (Wavemetrics, Lake Oswego, OR). We obtained the irregularity score $(S)$ of respiratory bursts using the methods described by Telgkamp et al. (2002) and the following formula: $S_{n}=100 \times \operatorname{ABS}\left(P_{n}-P_{n-1}\right) /$ $P_{n-1}$, where $S_{n}$ is the score of the $n$th cycle, $P_{n}$ is its period, $P_{n-1}$ is the period of the preceding burst, and ABS is the absolute value.

Pharmacology. ( \pm )-4-Iodo-2,5-dimethoxyamphetamine (DOI) $\mathrm{HCl}$, alaproclate hydrochloride, 5-methyl-1-(3-pyridylcarbamoyl)-1,2,3,5-tetrahydropyrrolo[2,3-f]indole (SB206553), cadmium chloride, $(+)$-bicuculline free base, strychnine $\mathrm{HCl},( \pm)-3$-(2-carboxypiperazin-4-yl)-propyl-1phosphonic acid (CPP), and 18 $\beta$-glycyrrhetinic acid were obtained from Sigma (St. Louis, MO). Ketanserine tartrate, spiperone, 4-(4fluorobenzoyl)-1-(4-phenylbutyl)-piperidine (piperidine), phorbol 12myristate 13-acetate (PMA), and 6-cyano-7-nitroquinoxaline-2,3-dione (CNQX) were obtained from Tocris Cookson (Ellisville, MO). None of these drugs caused a change in the LJP. The possibility of washing out $5-\mathrm{HT}_{2 \mathrm{~A}}$ antagonists was tested for ketanserine and piperidine. However, even after $40 \mathrm{~min}$ of wash-out after application of ketanserine, the frequency of respiratory activity remained decreased $(n=5)$, and it took $>1 \mathrm{hr}$ to achieve a partial recovery of respiratory activity after application of piperidine $(n=7)$. Because of the difficulty in reversing the effects of these antagonists, we performed only one pharmacological experiment per slice preparation, and we did not attempt a wash-out of 5-HT antagonists when assessing data obtained from intracellular recordings.

Statistical values are given as mean \pm SEM. The effects of the examined drugs were compared with the control condition as measured immediately before the drug application, and significance for these effects was assessed with a Student's paired $t$ test. Values were assumed to be significant at $p<0.05$.

\section{RESULTS}

\section{Effects of pharmacological activation and blockade of 5- $-\mathrm{HT}_{2 \mathrm{~A}}$ receptors}

Activation of $5-\mathrm{HT}_{2 \mathrm{~A}}$ receptors has excitatory effects on respiratory rhythm in the transverse slice preparation of mice (Fig. 1B), confirming studies performed in other in vitro preparations (AlZubaidy et al., 1996; Onimaru et al., 1998), as well as in anesthetized cats (Lalley et al., 1995) and conscious rats (Cayetanot et al., 2002). Application of DOI, a specific 5-HT $2 \mathrm{~A}$-receptor agonist (Marek and Aghajanian, 1996), increased the frequency of integrated population activity recorded from the PBC (Fig. $1 A, P B C$ int). As shown in Figure $1 B$, DOI increased the frequency of two types of respiratory bursts: small-amplitude bursts that represent "fictive eupneic activity" and large-amplitude bursts that represent "fictive sigh activity" as defined by Lieske et al. (2000). In the present study, we evaluated only the serotonergic effect on fictive eupneic activity as defined by Lieske et al. (2000) and refer to this activity as "fictive respiratory activity" or "respiratory activity" (small-burst) throughout this study. Frequency of fictive respiratory activity significantly increased to $143 \pm 14.2 \%$ of control during the application of DOI (Fig. 1C) $(n=13)$. Note that the increase in respiratory activity coincided with an increase in integrated baseline activity (Fig. $1 B$ ). The excitatory effect of DOI was mimicked by the blockade of endogenous 5-HT uptake with alaproclate $(10 \mu \mathrm{M})$. Confirming previous reports (Morin et al., 1990, 1991; Di Pasquale et al., 1994), the blockade of 5-HT uptake significantly increased the frequency of fictive respiratory activity to $125.84 \pm 4.91 \%$ of control $(n=5 ; p=0.016)$. The effects of DOI and the effects of the $5-\mathrm{HT}_{2 \mathrm{~A}}$ antagonists were consistent and similar throughout all ages of the examined animals (P1-P13).

Blockade of endogenous activation of the $5-\mathrm{HT}_{2 \mathrm{~A}}$ receptor had opposite effects on respiratory activity. Continuous application of the $5-\mathrm{HT}_{2 \mathrm{~A}}$-receptor antagonist ketanserine resulted in a progressive depression of fictive respiratory activity (Fig. $2 A$ ). This depression is reflected in a decrease in fictive respiratory frequency (to $42.93 \pm 4.84 \%$ of control) (Fig. $2 E$ ), burst amplitude (to $68.50 \pm 6.64 \%$ of control) (Fig. $2 F$ ), and integrated baseline activity (Fig. $2 A)(n=22)$. In three of 22 preparations, we observed that respiratory activity ceased 30-40 min after the application of ketanserine. In all preparations, respiratory rhythmic activity became more irregular in the presence of ketanserine (Fig. 2G). This was assessed by obtaining an irregularity score, as described previously by Telgkamp et al. (2002). Also see Materials and Methods.

Although ketanserine is a relatively specific $5-\mathrm{HT}_{2 \mathrm{~A}}$ antago- 
A

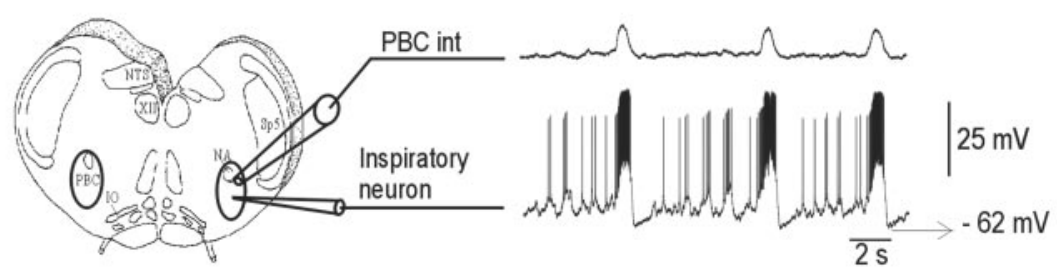

B

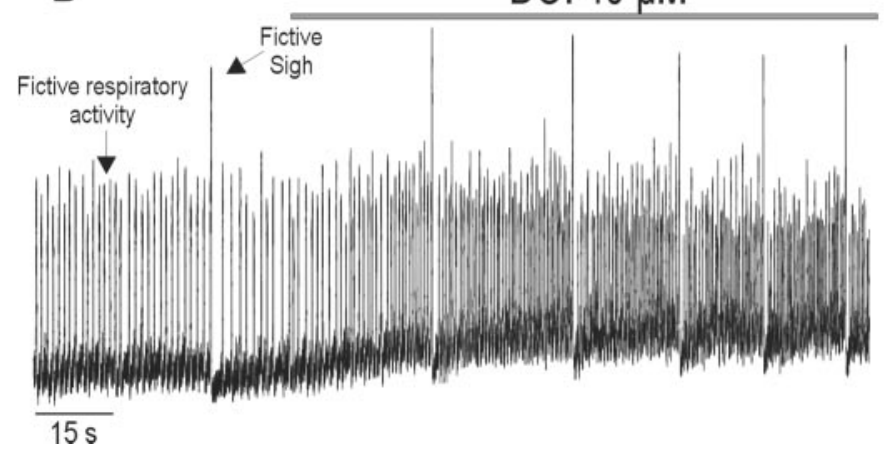

A

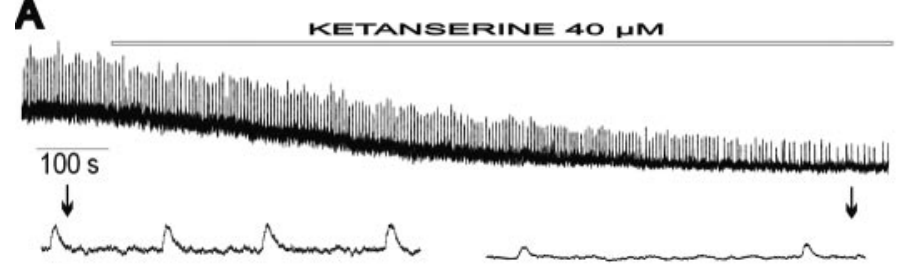

B

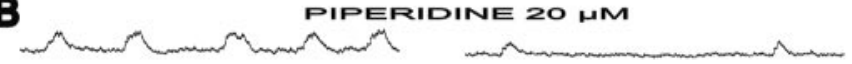

C
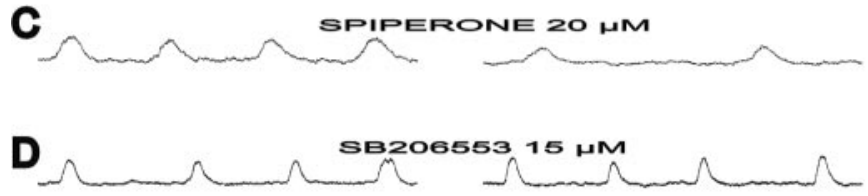

$2 \mathrm{~s}$

nist, we also confirmed this finding with other $5-\mathrm{HT}_{2 \mathrm{~A}}$-specific antagonists. The other two 5- $\mathrm{HT}_{2 \mathrm{~A}}$ antagonists examined, piperidine (Fig. 2B) and spiperone (Fig. 2C), had the same effects as ketanserine, causing a significant reduction in the frequency, amplitude, and regularity of the fictive respiratory rhythm. The quantification of the effect of these antagonists on the three respiratory parameters mentioned is shown in Figure $2 E-G$. The effect of these antagonists was dose dependent. Piperidine $(2 \mu \mathrm{M})$ produced a smaller but still significant reduction in the frequency of the fictive respiratory activity (to $88.57 \pm 6.13 \%$ of control; $n=4 ; p<0.05$ )

Studies in other systems indicate that $5-\mathrm{HT}_{2 \mathrm{~A}}$ antagonists can also act on the 5- $\mathrm{HT}_{2 \mathrm{C}}$ receptor (Baxter et al., 1995; Barnes and Sharp, 1999; Jerman et al., 2001). Although the 5-HT $\mathrm{H}_{2 \mathrm{~A}}$-receptor antagonists ketanserine, piperidine, and spiperone have a higher affinity for the $5-\mathrm{HT}_{2 \mathrm{~A}}$ receptor, it was important to compare their actions with those of a specific $5-\mathrm{HT}_{2 \mathrm{C}}$ antagonist (SB206553). Continuous application of SB206553, for the same period of time as the three $5-\mathrm{HT}_{2 \mathrm{~A}}$ antagonists (30 min), does not affect the fictive respiratory activity (Fig. 2D), further confirming that the effects of ketanserine, piperidine, and spiperone were
Figure 1. Activation of $5-\mathrm{HT}_{2 \mathrm{~A}}$ receptors has an excitatory effect on fictive respiratory rhythmic activity. $A$, Transverse slices that contain the pre-Bötzinger complex (left panel, $P B C$ int) spontaneously generate respiratory rhythmic population activity (right panel). Integrated population activity obtained from extracellular recordings (top trace, $P B C$ int) reveals bursts of inspiratory activity that are used as markers to identify intracellularly recorded neurons. Neurons with synaptic drive potentials occurring in phase with population bursts are referred to as inspiratory neurons (bottom trace). B, Integrated population activity reveals two types of fictive respiratory activities: small-amplitude bursts represent fictive respiratory activity; large-amplitude bursts represent fictive sighs. Note that exogenously applied DOI increases the frequency of both activities. $C$, The frequency increase in respiratory activity was plotted for 13 slices as a percentage of control. $I O$, Inferior olive; $N A$, nucleus ambiguus; NTS, nucleus tractus solitarius; $S p 5$, spinal trigeminal nucleus. ${ }^{*} p<$ 0.05 (Student's paired $t$ test) compared with control.
E

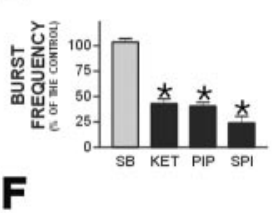

$\mathbf{F}$

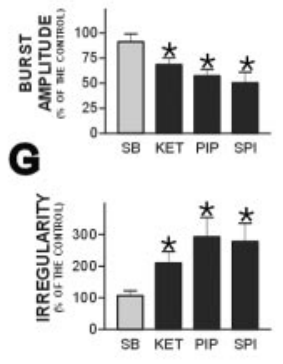

Figure 2. Blockade of endogenously activated $5-\mathrm{HT}_{2 \mathrm{~A}}$ receptors but not $5-\mathrm{HT}_{2 \mathrm{C}}$ receptors depresses fictive respiratory rhythmic activity. $A$, Integrated PBC activity shown at a slow (top trace) and fast (bottom traces) time scale. Note that ketanserine causes a gradual decrease in frequency, amplitude, and regularity of respiratory activity. The arrows show the time at which the bottom traces were taken. The effect of ketanserine is similar to the effect of two other $5-\mathrm{HT}_{2 \mathrm{~A}}$ antagonists, piperidine $(B)$ and spiperone $(C)$, but not to the effect of the specific $5-\mathrm{HT}_{2 \mathrm{C}}$ antagonist $\mathrm{SB} 206553(D)$, which has no effect on the fictive respiratory activity. $E-G$, Histograms plotting the percentage changes for burst frequency $(E)$, amplitude $(F)$, and irregularity $(G) . S B$, SB206553; KET, ketanserine; $P I P$, piperidine; $S P I$, spiperone. Note that significant changes were caused only by $5-\mathrm{HT}_{2 \mathrm{~A}}$ antagonists. ${ }^{*} p<0.05$ (Student's paired $t$ test) compared with control (data not shown).

attributable to a specific $5-\mathrm{HT}_{2 \mathrm{~A}}$-receptor modulation (for quantification, see Fig. $2 E-G)$.

The effects of blocking the $5-\mathrm{HT}_{2 \mathrm{~A}}$ receptor were examined in 34 inspiratory and nine expiratory neurons that had no pacemaker properties (nonpacemaker neurons). Only two of the recorded inspiratory neurons exhibited a hyperpolarization of $>4-5 \mathrm{mV}$ (Fig. 3A); all other recorded respiratory neurons showed no changes or only minor changes in membrane potential $(<3 \mathrm{mV}$ ) (Fig. 3B). On average, the membrane potential did not change significantly after the application of ketanserine (96.3 \pm $1.89 \%$ of control; $n=11)$, piperidine $(106.0 \pm 4.7 \%$ of control; $n=9)$, or spiperone $(94.8 \pm 2.7 \%$ of control; $n=4)$. As shown in Figure $4 B$, we also did not observe a significant change in the input resistance of the respiratory neurons throughout the application of the $5-\mathrm{HT}_{2 \mathrm{~A}}$ antagonist piperidine $(107.64 \pm 7.57 \%$ of control; $n=4)$.

Despite the absence of a significant alteration in either the membrane potential or the input resistance, ketanserine, piperidine, and spiperone significantly reduced the frequency of action potentials generated during the burst in all inspiratory nonpacemaker neurons [to $67.9 \pm 12.3 \%(n=11), 43.3 \pm 11.9 \%(n=7)$, 
Figure 3. Blockade of endogenously activated $5-\mathrm{HT}_{2 \mathrm{~A}}$ receptors reduces action potential discharge in inspiratory neurons. $A-B$, Top panels, Intracellular recording from two inspiratory neurons at a slow time scale. Population activity is not shown. Bottom panels, Intracellular recordings from the same inspiratory neurons before (left) and after (right) the application of piperidine. Intracellular recordings are shown at a faster time scale together with the simultaneously recorded integrated population activity (top traces). Arrows show approximately the time at which the bottom traces were taken. Note the reduction in the amplitude of the spontaneous action potentials during the interburst interval (which is dramatic in the neurons shown in $A$ ) and during the population burst (for comparison, see the line).

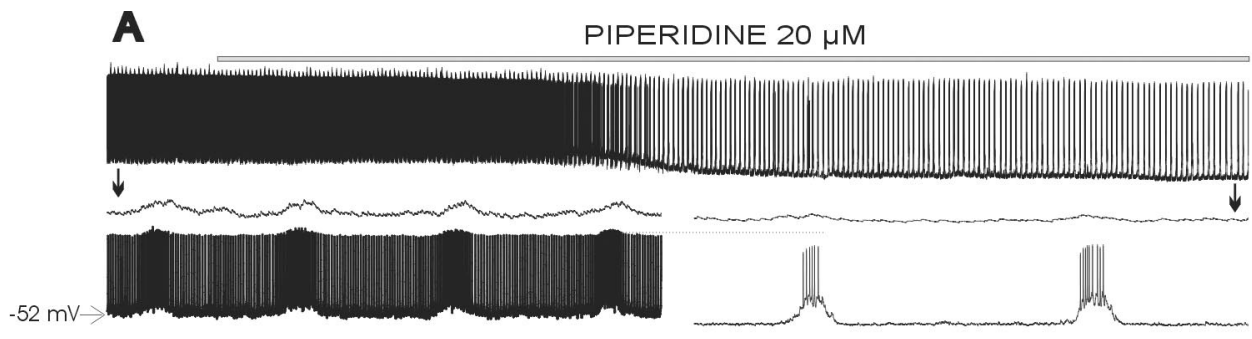

B
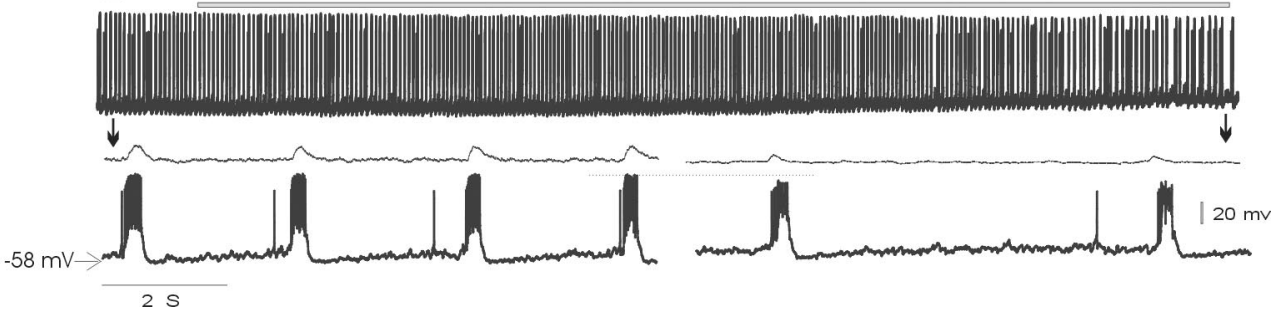

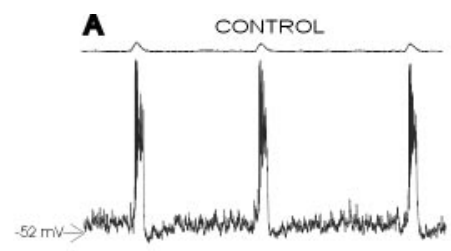

COCKTAIL
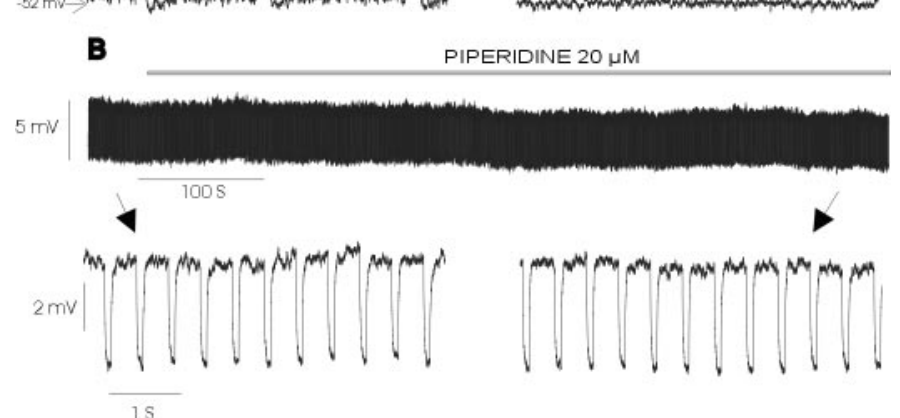

$\mathbf{C}$

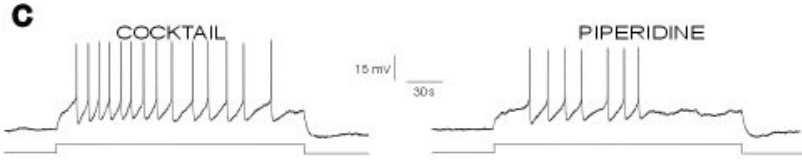

Figure 4. Blockade of $5-\mathrm{HT}_{2 \mathrm{~A}}$ receptors reduces the amplitude and number of action potentials but does not change the input resistance of synaptically isolated inspiratory neurons. $A$, Blockade of synaptic transmission with the mixture containing $\mathrm{CPP}, \mathrm{CNQX}$, bicuculline, and strychnine $(10,20,20$, and $1 \mu \mathrm{M}$, respectively; COCKTAIL) eliminates rhythmic population activity (top trace) and burst activity in the nonpacemaker neuron (bottom trace). $B$, Top panel, Intracellular recording from the same inspiratory neurons as shown in $A$ in the presence of the mixture shown at a slow time scale during the application of a test pulse of hyperpolarizing current. Bottom panel, Intracellular recording from the same inspiratory neuron before (left) and after (right) the application of piperidine; note that continuous application of piperidine does not affect the input resistance. Arrows show the time at which the bottom traces were taken. $C$, Effect of piperidine on action potential discharge evoked by pulses of depolarizing current injected into a synaptically isolated inspiratory neuron. Note that the number and amplitude of action potentials are reduced after the application of piperidine.

and $44.53 \pm 26.84 \%(n=6)$ of control frequency, respectively]. This effect is illustrated for the application of piperidine (Fig. $3 A, B)$. The reduction in the frequency of action potentials was not restricted to the intraburst activity of inspiratory neurons. In the inspiratory neurons that generated action potentials during the interburst interval $(n=14)$ (Fig. $3 A)$, there was also a significantly reduced interburst action potential frequency [to $16.6 \pm$ $9.4 \%(n=8)$ and $20.2 \pm 11.8 \%(n=6)$ of control for ketanserine and piperidine, respectively]. These effects were not specific to inspiratory neurons. Expiratory neurons are tonically active during the interburst interval and are hyperpolarized during the inspiratory burst. After the application of ketanserine, action potential discharge was also reduced in expiratory neurons (to $32.9 \pm 11.35 \%$ of control; $n=9)$. Three of the expiratory neurons ceased to discharge (data not shown). The reduced action potential discharge in both inspiratory and expiratory neurons can explain, at least in part, the reduction in the baseline of the integrated population recording. As shown in Figure 3, the reduction in action potential discharge is reflected not just in the frequency of the action potential; there was also a reduction in the amplitude of the action potentials generated by the respiratory neurons after the application of the $5-\mathrm{HT}_{2 \mathrm{~A}}$ antagonist.

The observed changes in the characteristics of action potential discharge could be attributable indirectly to a network effect (i.e., reduction of synaptic drive). To test this possibility, we synaptically isolated seven inspiratory neurons by applying a mixture of antagonists for NMDA receptor- and non-NMDA receptordependent glutamatergic (10 $\mu \mathrm{M}$ CPP, $20 \mu \mathrm{M}$ CNQX), glycinergic, and GABAergic synaptic transmission (1 $\mu \mathrm{M}$ strychnine, 20 $\mu \mathrm{M}$ bicuculline). We evoked a train of action potentials in each of the examined neurons by injecting the same amount of depolarizing current before and after the application of piperidine. The experiment shown in Figure $4 C$ confirms that the blockade of 5-HT $\mathrm{HA}_{2 \mathrm{~A}}$ receptors affected action potential discharge. The application of piperidine reduced the number of action potentials by $33.01 \pm 10.40 \%$ and reduced the amplitude of the action potentials to $80.62 \pm 4.94 \%$ of control $(p=0.004)$. The duration of the action potentials was not affected (control, $2.06 \pm 0.16 \mathrm{msec}$; piperidine, $2.53 \pm 0.66 \mathrm{msec}$ ).

\section{PKC activation prevents inhibition of the respiratory rhythm by $5-\mathrm{HT}_{2 \mathrm{~A}}$ antagonists}

5- $\mathrm{HT}_{2}$ receptors are positively coupled to phospholipase $\mathrm{C}$, which causes the intracellular release of diacylglycerol and inositol triphosphate and a subsequent activation of PKC (Martin and Humphrey, 1994; Egan et al., 1998; Barnes and Sharp, 1999; 

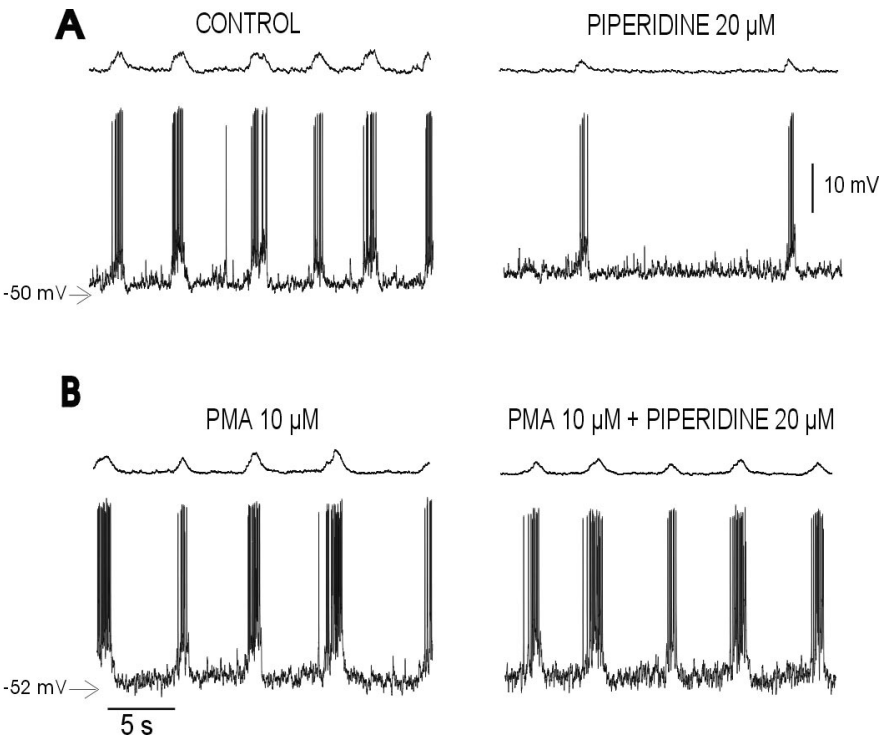

Figure 5. Activation of PKC opposes the respiratory depression caused by the $5-\mathrm{HT}_{2 \mathrm{~A}}$ blockade. Integrated $\mathrm{PBC}$ activity (top traces) simultaneously recorded with an inspiratory neuron (bottom traces) under control conditions and after the application of piperidine $(A)$ and in the presence of PMA $(B)$ is shown. Note that the PKC activator abolished the depression in population activity and the discharge pattern of the inspiratory neuron produced by piperidine $(B)$.

Rauser et al., 2001). Therefore, activators of PKC (phorbol esters) can mimic the effects of $5-\mathrm{HT}_{2 \mathrm{~A}}$ activation (Wang and Friedman, 1990; Araneda and Andrade, 1991; Blank et al., 1996). Consequently, we hypothesized that the blockade of endogenous activation of $5-\mathrm{HT}_{2 \mathrm{~A}}$ receptors causes a reduced activation of $\mathrm{PKC}$, which then results in a depression of the respiratory rhythm. If this is the case, activation of PKC with a phorbol ester should prevent the inhibition produced by piperidine. To test this hypothesis, brainstem slices were pretreated with the phorbol ester PMA $(10 \mu \mathrm{M})$ for $10 \mathrm{~min}$. The incubation with PMA produced a slight, but not significant, excitatory effect on the respiratory rhythm by itself and, consistent with our hypothesis, prevented the depression in the respiratory activity produced by the blockade of the $5-\mathrm{HT}_{2 \mathrm{~A}}$ receptors (Fig. $5 A, B$ ). Preincubation with PMA can prevent the reduction in respiratory frequency $[67.09 \pm 10.26 \%$ of control with PMA plus piperidine $(n=5)$ vs $40.34 \pm 4.05 \%$ of control with piperidine alone $(n=20)]$, the increase in the irregularity [125.12 $\pm 32 \%$ of control with PMA plus piperidine $(n=5)$ vs $53278.75 \pm 62.18 \%$ of control with piperidine alone $(n=20)]$, and the reduction in action potential frequency $[102 \pm 12.9 \%$ of control with PMA plus piperidine $(n=5)$ vs $43.3 \pm 11.9 \%$ of control with piperidine alone $(n=10)]$ produced by piperidine.

\section{$5-\mathrm{HT}_{2 \mathrm{~A}}$ antagonists differently affect cadmium- insensitive and cadmium-sensitive pacemaker activity}

After blockade of respiratory network activity with CNQX, some inspiratory neurons continue to exhibit endogenously generated pacemaker activity (Smith et al., 2000; Thoby-Brisson et al., 2000; Thoby-Brisson and Ramirez, 2001; Del Negro et al., 2002). Because of their potential role in generating the respiratory rhythm (Rekling and Feldman, 1998; Butera et al., 1999; McCrimmon et al., 2000; Smith et al., 2000), we examined the effects of 5-HT $2 \mathrm{~A}$ antagonists on this pacemaker activity. Pacemaker neurons were synaptically isolated by applying the mixture containing CPP,
CNQX, bicuculline, and strychnine as described above plus a gap-junction blocker (50 $\mu \mathrm{M} 18 \beta$-glycyrrhetinic acid). The PBC contains two types of pacemaker neurons (Thoby-Brisson and Ramirez, 2001) with different burst properties (compare Fig. $6 D$ with Fig. 7C) and different sensitivity to cadmium at concentrations (100-200 $\mu \mathrm{M})$ known to block all calcium currents (Elsen and Ramirez, 1998). Therefore, we separated the pacemaker neurons into two groups: cadmium-sensitive and cadmiuminsensitive pacemaker neurons (Thoby-Brisson and Ramirez, 2001). Both types of pacemaker neurons fire in phase with the fictive respiratory rhythm and, after the synaptic isolation with the mixture, continue to produce rhythmic burst activity (see middle traces of Figs. $6 A$ and $7 A$ for cadmium-insensitive and cadmium-sensitive pacemakers, respectively). In the presence of cadmium $(200 \mu \mathrm{M})$, cadmium-insensitive pacemakers continue to generate burst activity (Fig. 6B, middle trace), whereas pacemakers in cadmium-sensitive neurons cease to burst (Fig. $7 A$, bottom trace). In the presence of $5-\mathrm{HT}_{2 \mathrm{~A}}$-receptor antagonists, cadmiuminsensitive pacemaker activity ceased (Fig. 6A,B). The complete cessation of pacemaker activity was preceded by a significant reduction in the frequency of pacemaker bursts, which we quantified for 18 cadmium-insensitive pacemaker neurons 30 min after the application of piperidine (Fig. $6 C$ ). This complete blockade of cadmium-insensitive burst activity was also evident when burst activity was electrically evoked by the application of DC. A square pulse of current injected into a pacemaker neuron evoked burst activity before the blockade of the $5-\mathrm{HT}_{2 \mathrm{~A}}$ receptor (Fig. $6 E$ ). After the application of piperidine, the same amount of current produced just a few isolated action potentials. This was seen in all pacemakers tested with this experimental paradigm $(n=3)$. As observed for the nonpacemaker neurons, cadmium-insensitive pacemakers also showed a significant reduction in the amplitude of action potentials, reducing the action potential amplitude to $92.96 \pm 1.81 \%$ of control $(p=0.01)$. The frequency of action potentials generated during each burst decreased to $16.74 \pm$ $13.50 \%$ of control ( $p=0.00002$ ) (Fig. $6 A, B$, bottom traces).

In cadmium-sensitive pacemaker neurons, piperidine also significantly reduced the frequency (to $74.76 \pm 15.08 \%$ of control) and amplitude (to $78.59 \pm 6.44 \%$ of control) of action potentials generated during each burst. However, burst activity persisted in all examined cadmium-sensitive pacemaker neurons $(n=10)$ (Fig. 7A, third trace). The recording of the same cadmiumsensitive pacemaker neuron (Fig. $7 A$ ) is shown at a slow time scale (Fig. $7 B$ ) to illustrate that pacemaker activity continued to persist in the presence of piperidine for a long time. The blockade of the $5-\mathrm{HT}_{2 \mathrm{~A}}$ receptors with piperidine did not alter the burst frequency (control, $0.50 \pm 0.11 \mathrm{~Hz}$; piperidine, $0.52 \pm 0.09 \mathrm{~Hz}$ ); however, there was a significant reduction in the duration of the burst (control, $2.32 \pm 0.43 \mathrm{sec}$; piperidine, $1.86 \pm 0.32 \mathrm{sec}$ ) and an increase in the burst amplitude (control, $11.36 \pm 1.63 \mathrm{mV}$; piperidine, $15.44 \pm 1.18 \mathrm{sec}$ ). Note that the action potential reduction was more pronounced in cadmium-sensitive pacemaker neurons than in cadmium-insensitive pacemakers. Therefore, it is likely that the increased burst amplitude contributed to the reduction in the action potential amplitude in cadmium-sensitive pacemaker neurons.

\section{Time course of network and cellular effects produced by $5-\mathrm{HT}_{2 \mathrm{~A}}$ antagonists}

The data presented so far indicate that blockade of an endogenous activation of $5-\mathrm{HT}_{2 \mathrm{~A}}$ receptors results in alterations at the cellular as well as the network level. Figure 8 compares the time 
Figure 6. Blockade of endogenously activated $5-\mathrm{HT}_{2 \mathrm{~A}}$ receptors abolishes pacemaker properties in cadmium-insensitive pacemaker neurons. $A, B$, Top panel, Two inspiratory neurons recorded in different slices (bottom traces) discharging in phase with integrated population activity (top panel) under control conditions. Middle panel, After the blockade of respiratory population activity with the mixture (COCKTAIL) in $A$ or mixture plus 200 $\mu \mathrm{M}$ cadmium in $B$ (top trace), the pacemaker neurons continue to generate intrinsically rhythmic activity (middle trace), which is abolished after the application of piperidine (bottom panel). C, Histogram plotting the average spontaneous burst frequency of 18 cadmiuminsensitive pacemaker neurons before $(C O N)$ and after $(P I P)$ the application of piperidine. $D$, Expanded trace of a single burst recorded in a cadmium-insensitive pacemaker neuron under control conditions and in the presence of piperidine. $E$, Burst activity evoked in a cadmiuminsensitive pacemaker neuron (top trace) by the application of a square pulse of depolarizing DC (bottom trace). The same pulse evokes only isolated action potentials after the application of piperidine (middle trace). Note also a reduction in action potential amplitude and frequency in the presence of piperidine. $* p<0.05$ (Student's paired $t$ test) compared with control.

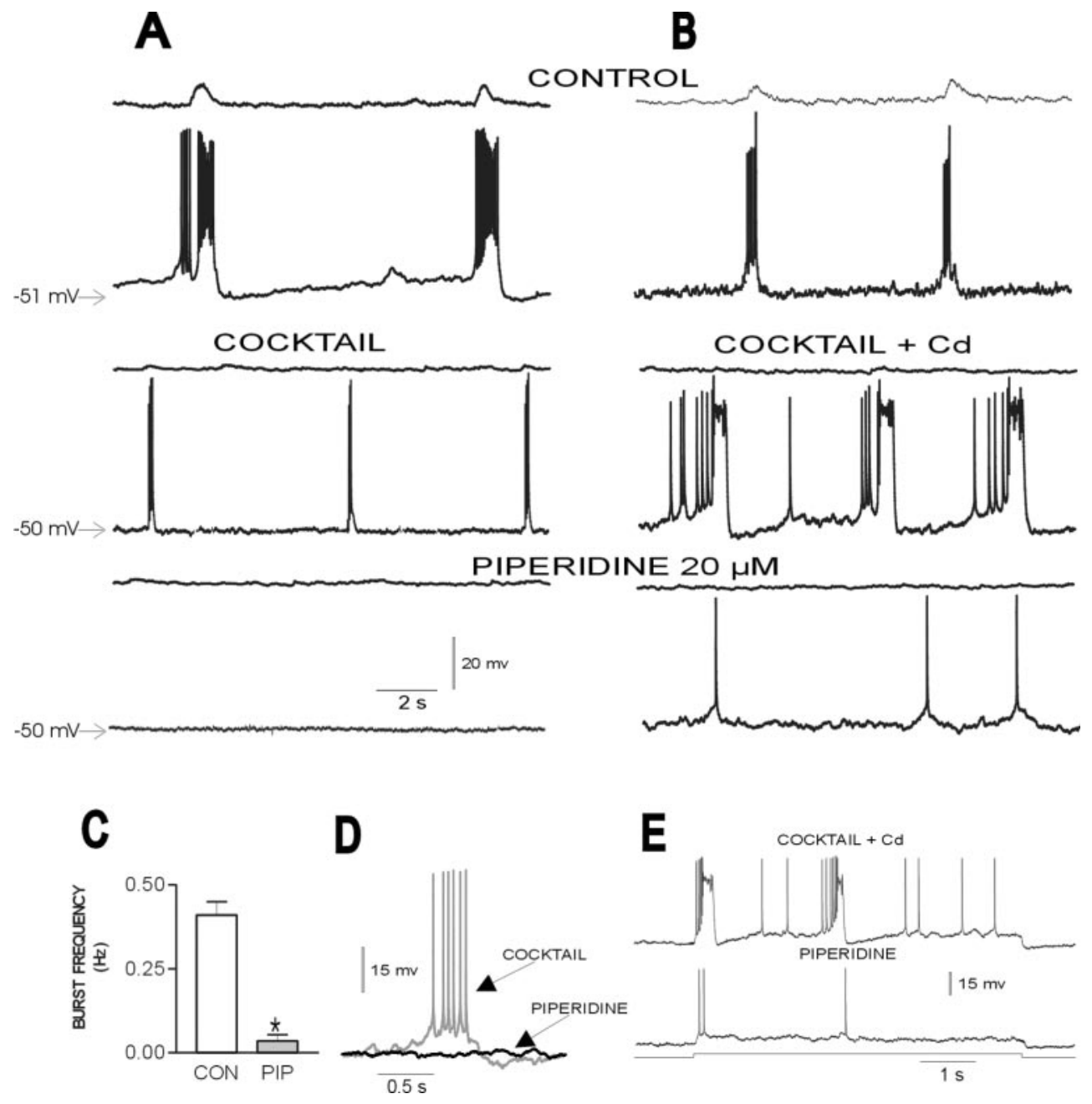

ings from 11 inspiratory nonpacemaker neurons (Fig. 9A) in the voltage-clamp configuration. Voltage steps from -80 to $+40 \mathrm{mV}$ (Fig. 9C) and slow voltage ramps from -80 to $+20 \mathrm{mV}$ (Fig. 9B) $(90 \mathrm{mV} / \mathrm{sec})$ were applied to elicit transient and persistent $\mathrm{Na}^{+}$ currents, respectively. As shown in Figure 9, both the transient (Figs. 9C, top trace, 9D) and the persistent (Fig. 9B, top trace) sodium current were inhibited after the application of the $5-\mathrm{HT}_{2 \mathrm{~A}}$ antagonist ketanserine. The bottom traces in Figure 9, $B$ and $C$, show that both the persistent and the transient inward currents recording in the nonpacemaker neurons were sensitive to TTX.

\section{DISCUSSION}

In this study, we demonstrated in the transverse brainstem slice preparation of mice that the blockade of 5- $\mathrm{HT}_{2 \mathrm{~A}}$ receptors produces a depression in fictive respiratory activity. This respiratory depression was reflected in a significant reduction in frequency, amplitude, and regularity of respiratory rhythmic activity that could be prevented by activation of the PKC pathway. The blockade of $5-\mathrm{HT}_{2 \mathrm{~A}}$-receptor activity resulted in a significant reduction in action potential discharge and cadmium-insensitive, TTXsensitive, pacemaker activity. This leads to the conclusion that activation of $5-\mathrm{HT}_{2 \mathrm{~A}}$ receptors is required not only for maintaining action potential discharge but also for pacemaker activity in neurons that are thought to rely on the activation of the persistent sodium current. To exclude the possibility that the observed effects were attributable to an unspecific action on other recep- pothesis that the inhibition of $5-\mathrm{HT}_{2 \mathrm{~A}}$ receptors affects both the transient and the persistent sodium currents, we obtained record-

\section{Inhibition of the respiratory rhythm produced by $5-\mathrm{HT}_{2 \mathrm{~A}}$ antagonists is consistent with a red
both transient and persistent $\mathrm{Na}^{+}$currents}

The data presented are consistent with the hypothesis that blockade of an endogenous activation of $5-\mathrm{HT}_{2 \mathrm{~A}}$ receptor affects (1) action potential discharge and presumably, therefore, the activation of the transient sodium current, and (2) pacemaker activity in cadmium-insensitive pacemaker neurons and presumably, therefore, TTX-sensitive persistent sodium current. To test the hy- 

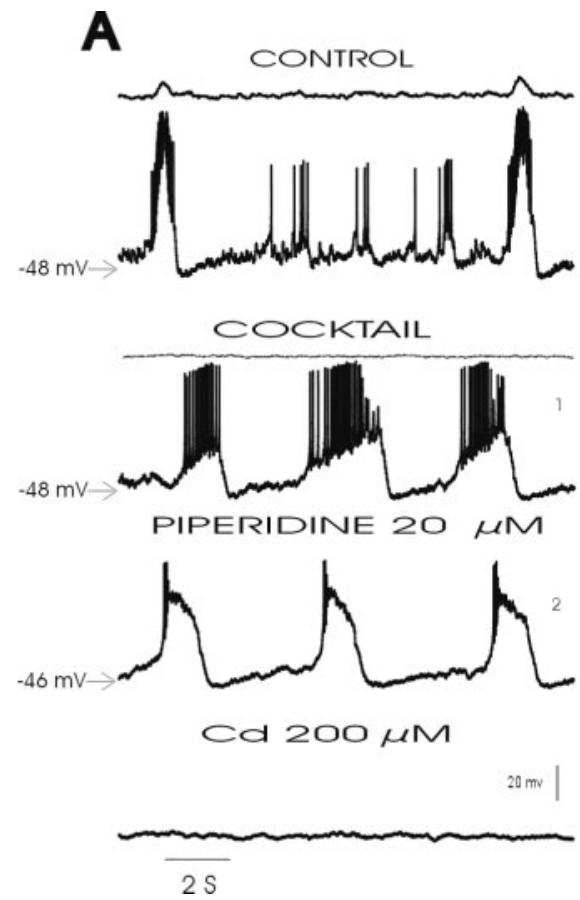
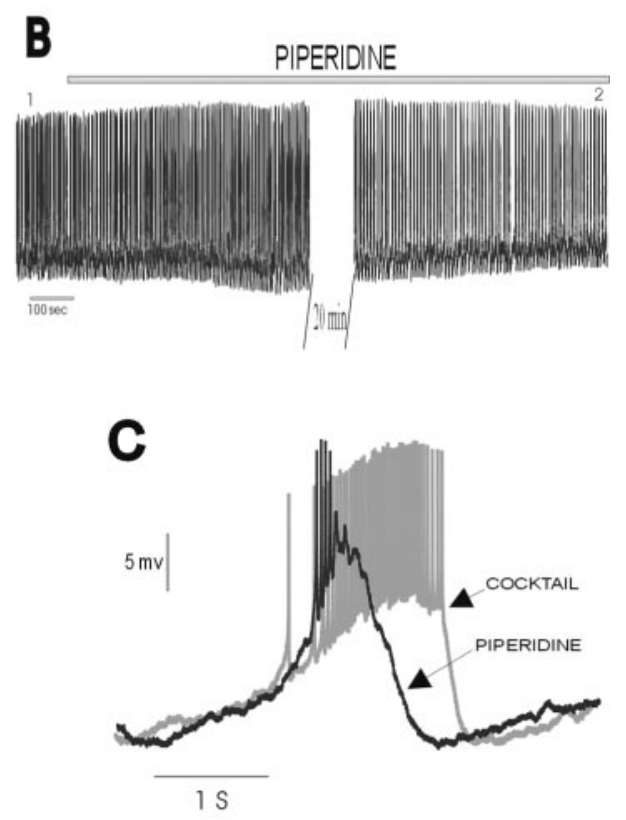

Figure 7. Blockade of endogenously activated $5-\mathrm{HT}_{2 \mathrm{~A}}$ receptors inhibits action potential discharge but not pacemaker properties in cadmium-sensitive pacemaker neurons. $A$, Top panel, Inspiratory neuron (bottom traces) discharging in phase with integrated population activity (top panel) under control conditions. Second panel, After the blockade of respiratory population activity with the mixture (COCKTAIL; top trace), the pacemaker neuron continues to generate intrinsically rhythmic activity (bottom trace). Third panel, Pacemaker activity persists, but action potential discharge is reduced after the application of piperidine. Fourth panel, Blockade of calcium currents with cadmium abolishes pacemaker activity. $B$, Intracellular recording of the same neuron as shown in $A$ at a slow time scale to illustrate the persistence of pacemaker activity even after a long exposure to piperidine. The numbers 1 and 2 show the time at which the traces in the mixture and after piperidine were taken to make $A$. $C$, Expanded trace of a single burst recorded in another cadmium-sensitive pacemaker neuron before (COCKTAIL) and after (PIPERIDINE) the application of piperidine. Note that the duration of the burst is reduced and the amplitude is increased after the application of piperidine. tors, we examined the effect of not one but three specific $5-\mathrm{HT}_{2 \mathrm{~A}}$ antagonists: ketanserine, piperidine, and spiperone. We excluded a possible action on $5-\mathrm{HT}_{2 \mathrm{C}}$ receptors by comparing the effects caused by $5-\mathrm{HT}_{2 \mathrm{~A}}$ antagonists with those caused by a specific $5-\mathrm{HT}_{2 \mathrm{C}}$ receptor antagonist, SB206553. Furthermore, our data are consistent with the known actions of $5-\mathrm{HT}_{2 \mathrm{~A}}$ receptors, as discussed in the following section.

\section{Role of endogenous activation of $5-\mathrm{HT}_{2 \mathrm{~A}}$ in the maintenance of respiratory rhythmic activity}

Activation of $5-\mathrm{HT}_{2 \mathrm{~A}}$ receptors has a well documented excitatory effect not only in the respiratory network but also on different areas in the CNS (Araneda and Andrade, 1991; Lindsay and Feldman, 1993; Marek and Aghajanian, 1996). At the cellular level, ionophoresis of $5-\mathrm{HT}_{2 \mathrm{~A}}$ agonists ( $\alpha$-Me-5-HT and DOI) depolarizes membrane potential and increases action potential frequency in respiratory neurons (Lalley et al., 1995; Onimaru et al., 1998), which results in an increase in respiratory rhythmic activity in the brainstem slice preparation (Al-Zubaidy et al., 1996; Onimaru et al., 1998). This is consistent with the DOI effects described in the present study (Fig. 1). The effects of exogenously applied $5-\mathrm{HT}_{2 \mathrm{~A}}$ agonists were opposite to those caused by the pharmacological blockade of $5-\mathrm{HT}_{2 \mathrm{~A}}$ receptors, which resulted in an inhibition of respiratory activity. This inhibitory effect was presumably attributable to a decreased activation of the PKC pathway, which is consistent with previous studies indicating not only that $\mathrm{PKC}$ is endogenously active in respiratory cells, but also that inhibition of this protein kinase depresses neuronal activity (Haji et al., 1996; Richter et al., 1997). The effects by DOI were mimicked by the blockade of endogenous 5-HT uptake, suggesting that the tonic activation of PKC is maintained at least in part by the endogenous release of 5-HT acting on $5-\mathrm{HT}_{2 \mathrm{~A}}$ receptors. In addition, it is conceivable that $5-\mathrm{HT}_{2 \mathrm{~A}}$ receptors are constitutively activated. This has been shown for a natural isoform of the $5-\mathrm{HT}_{2 \mathrm{C}}$ receptor (Rauser et al., 2001). Indeed, ketanserine can reduce the activity of consti- tutively activated $5-\mathrm{HT}_{2 \mathrm{~A}}$ receptors, acting as an inverse agonist (Egan et al., 1998). The 5- $\mathrm{HT}_{2}$ receptors are known to be linked to the $\mathrm{G}_{\mathrm{q}}$ family of $\mathrm{G}$-proteins, and subsequent activation of phospholipase $\mathrm{C}$ causes an increase in intracellular calcium and the activation of PKC (Martin and Humphrey, 1994; Barnes and Sharp, 1999; Rauser et al., 2001). Exogenously applied 5-HT and the $5-\mathrm{HT}_{2 \mathrm{~A}}$ agonist DOI increase PKC activity, and the increase in PKC induced by $5-\mathrm{HT}$ can be prevented by $5-\mathrm{HT}_{2 \mathrm{~A}}$ antagonists (Wang and Friedman, 1990). Furthermore, there is evidence that activation of PKC by phorbol esters mimics the excitatory actions of $5-\mathrm{HT}_{2 \mathrm{~A}}$ agonists in respiratory neurons (Champagnat and Richter, 1993; Lalley et al., 1995). Conversely, the excitability of respiratory neurons is depressed when PKC is inhibited (Haji et al., 1996). For rat pups, it has been shown that the PKC inhibitor Ro 32-0432 (3-[8-[(dimethylamino)methyl]6,7,8,9-tetrahydropyrido-[1,2-a]indol-10-yl]-4-(1-methyl-3indolyl)-H-pyrrole-2,5-dione hydrochloride) decreases the respiratory rate, suggesting that endogenous PKC inhibition results in a ventilatory reduction by affecting the timing mechanisms (Bandla et al., 1999), which is also consistent with the present study.

The activation of $\mathrm{PKC}$ and $5-\mathrm{HT}_{2 \mathrm{~A}}$ receptors also may have converging roles in controlling neuronal excitability (Bobker and Williams, 1990; Hwang and Dun, 1999) (for review, see Walaas and Greengard, 1991). Consistent with our findings, PKC modulates transient (Astman et al., 1998; Sitges et al., 1998; Schreibmayer, 1999) and persistent sodium currents (Astman et al., 1998; Franceschetti et al., 2000), and it has been proposed that these effects on sodium currents increase the neuronal excitability (Astman et al., 1998; Franceschetti et al., 2000). The activation of $5-\mathrm{HT}_{2 \mathrm{~A}}$ receptors has been associated with the induction of a tonic inward current (Lindsay and Feldman, 1993) that is $\mathrm{Na}^{+}$ dependent (Lee et al., 1999). In this study, we show that the inhibition of endogenous activation of $5-\mathrm{HT}_{2 \mathrm{~A}}$ receptors decreases the persistent and transient sodium current in the re- 


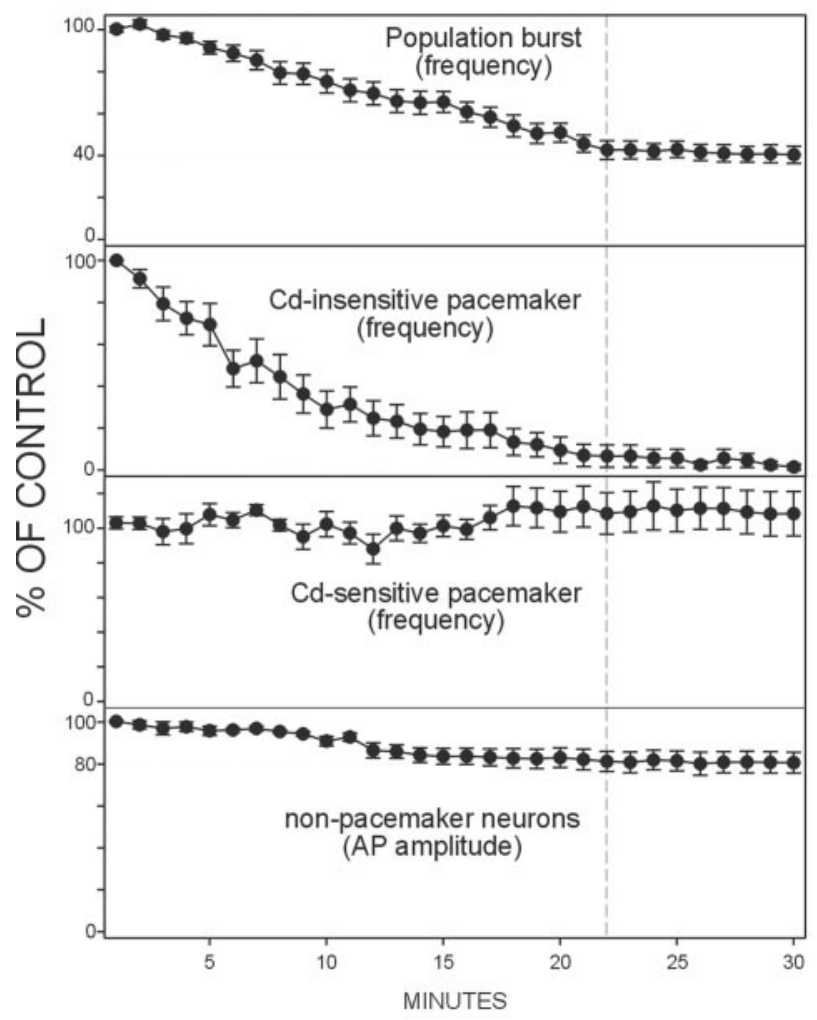

Figure 8. Time course of the effects of blockade of the $5-\mathrm{HT}_{2 \mathrm{~A}}$ receptor on the respiratory network at the population and cellular level. The effects of piperidine are shown for the frequency of fictive respiratory activity in the top panel $(n=20)$, for the frequency of bursting in synaptically isolated cadmium-insensitive pacemakers in the second panel $(n=18)$, for the frequency of bursting in synaptically isolated of cadmium-sensitive pacemakers in the third panel $(n=10)$, and for the amplitude of the evoked action potentials $(A P)$ in synaptically isolated nonpacemaker neurons in the bottom panel $(n=7)$. Bath application of $20 \mu \mathrm{M}$ piperidine started at $t=0$ and continued during the remainder of the experiment. Note that the reduction in the frequency of the population activity follows the reduction in the frequency of the cadmium-insensitive pacemaker and the reduction in the amplitude of the action potential in the nonpacemaker neurons. The stippled vertical line indicates the time at which the frequency of the respiratory network reaches a steady state at $40 \%$ of control.

corded nonpacemaker neurons. A modulation of both the transient and the persistent sodium current by $5-\mathrm{HT}_{2 \mathrm{~A}}$ receptors has been demonstrated in the prefrontal cortex (Carr et al., 2002).

\section{Role of sodium-dependent burst activity in respiratory rhythm}

A slowly inactivating persistent sodium current has been demonstrated in pacemaker neurons (Koshiya and Smith, 2000; Del Negro et al., 2002) and is postulated to underlie pacemaker activity in pre-Bötzinger neurons (Butera et al., 1999; Smith et al., 2000; Del Negro et al., 2002). Indeed, all pacemaker neurons in the $\mathrm{PBC}$ cease to generate pacemaker activity in the presence of TTX (Thoby-Brisson and Ramirez, 2001). Neurons in the PBC express two types of sodium channel subunits (Nav1.1 and Nav1.6), which may mediate pacemaker activity (McCrimmon et al., 2001). Modeling studies indicate that the slowly inactivating persistent sodium current has the biophysical characteristics to produce bursting activity, which could play an important role in the generation of respiratory network activity (Smith et al., 2000). The depression in the frequency, amplitude, and regularity of respiratory rhythmic activity as demonstrated in the present study is best explained, therefore, by the suppression of the persistent sodium current in cadmium-insensitive pacemaker neurons. It should be noted, however, that we demonstrated the reduction in the persistent sodium current for nonpacemaker neurons, because none of the neurons characterized in the present study in voltage clamp were pacemaker neurons. Although not the major focus, the effects of exogenously activated $5-\mathrm{HT}_{2 \mathrm{~A}}$ receptors with DOI were opposite to those of blocking the endogenously activated $5-\mathrm{HT}_{2 \mathrm{~A}}$ receptors. Therefore, it is conceivable that the increased network activity is attributable to an activation of the persistent sodium current in cadmium-insensitive pacemaker neurons, a hypothesis that can be tested in future studies.

Our finding is directly relevant to a recent study by Del Negro et al. (2002) that suggests that blockade of the persistent sodium current with riluzole does not abolish respiratory rhythm generation. This is consistent with our finding, because rhythm generation continued in the majority of preparations, although bursting in cadmium-insensitive pacemaker neurons was blocked in the presence of $5-\mathrm{HT}_{2 \mathrm{~A}}$ antagonists. In Figure 8, we show that the reduction in the frequency of fictive respiratory rhythm coincided with the reduction in the frequency of cadmium-insensitive pacemaker activity, which is consistent with modeling studies by Butera et al. (1999). Furthermore, the maximal reduction in the depression of the respiratory activity occurred at the same time as the complete blockade of cadmium-insensitive pacemaker activity. Interestingly, as suggested by Del Negro et al. (2002), fictive respiratory rhythm was still generated. However, it is important to note that the persistence of respiratory rhythm generation in our study does not demonstrate that pacemaker neurons play no role in rhythm generation, because cadmium-sensitive pacemaker neurons remained rhythmically active. In fact, our finding suggests that the cadmium-insensitive pacemaker neurons play an important role in the production of regular respiratory activity, because the respiratory rhythm generation was depressed and became irregular despite the persistence (and even enhancement) of pacemaker activity in cadmium-sensitive pacemaker neurons. It must be emphasized, however, that it is very difficult to reach a causal conclusion in a functional network. First, although intrinsic bursting was suppressed in the isolated cadmiuminsensitive pacemaker neurons, in the functional network these neurons will still be synaptically driven in phase with inspiration. Therefore, they still presumably will contribute to rhythm generation even in the absence of these specific bursting properties. Second, spike discharge also was affected by the blockade of the endogenous $5-\mathrm{HT}_{2 \mathrm{~A}}$ receptor activation. Therefore, it is most likely that network effects also contribute to the observed depression in respiratory activity, which is consistent with the study by Del Negro et al. (2002). In this context, it is worth mentioning that the effect of riluzole on cadmium-sensitive pacemaker neurons was not specifically examined by Del Negro et al. (2002). Therefore, the relative contribution and interaction of network elements and the different types of pacemaker neurons remain one of the most important, but still unresolved, issues that need to be unraveled to understand how the respiratory rhythm is generated.

We conclude that the endogenous activation of $5-\mathrm{HT}_{2 \mathrm{~A}}$ receptors plays a critical role in maintaining respiratory activity by continuously modulating the persistent and transient sodium current via the PKC pathway. The observed network effects underline the importance of neuromodulators, such as 5-HT, in adjusting ionic conductances that are crucial for regulating both 
A

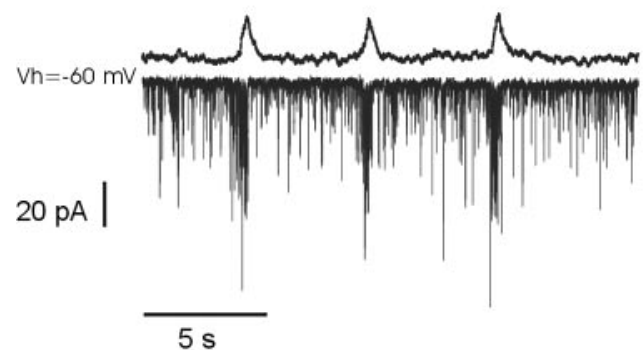

C

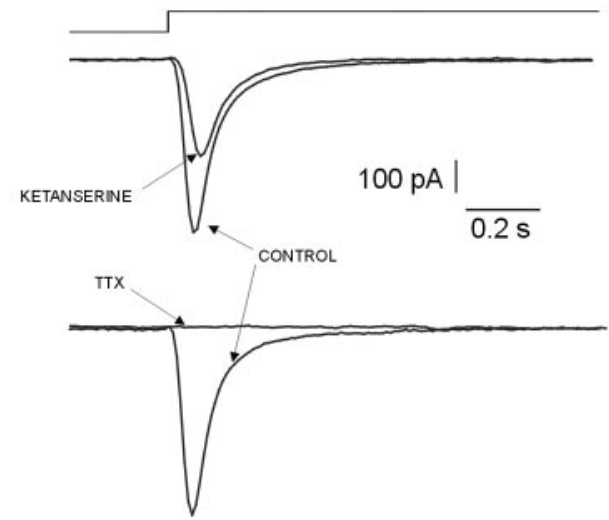

B
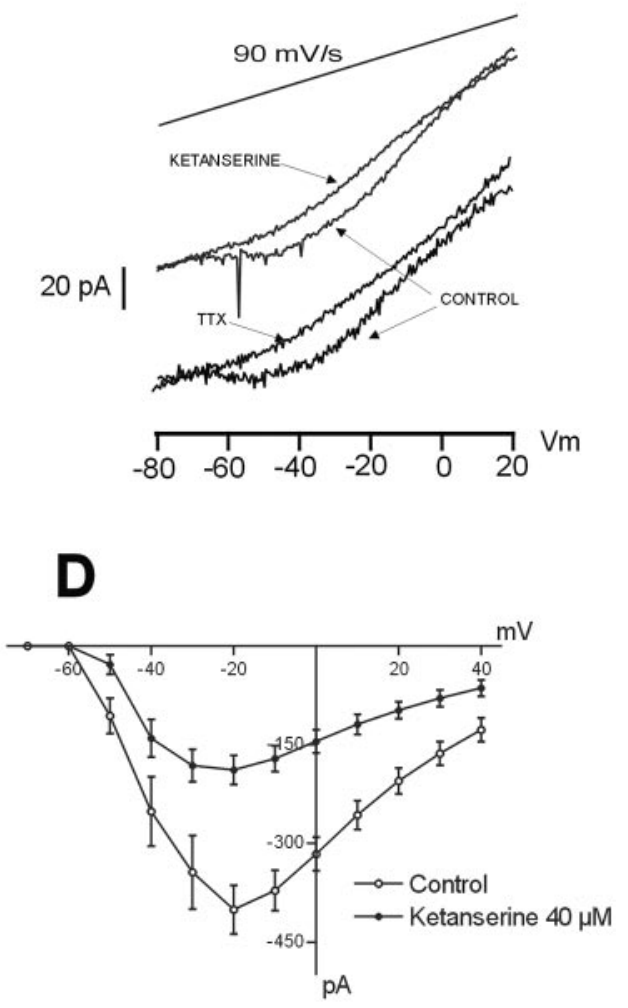

Figure 9. Blockade of endogenous activation of $5-\mathrm{HT}_{2 \mathrm{~A}}$ receptors reduces fast and persistent sodium currents. $A$, Inspiratory neuron recorded under voltageclamp condition (bottom trace) simultaneously with integrated population activity. The inward current observed in the neuron under voltage-clamp conditions represents rhythmic synaptic drive current produced by the network activity. $B$, After the blockade of calcium $(200 \mu \mathrm{M}$ $\mathrm{Cd}^{2+}$ ) and potassium (30 mM tetraethylammonium) currents, the same neuron exhibits a persistent sodium current in response to a voltage ramp, which is blocked after the application of ketanserine. $C$, Fast transient sodium current evoked by voltage steps from -80 to -20 $\mathrm{mV}$ was reduced in the presence of ketanserine. Note that the long voltage step will also evoke the persistent sodium current. Its slow inactivation, therefore, also will contribute to the time course of the evoked sodium current. $D, I-V$ curve for the transient sodium current obtained before and after the application of ketanserine. Each point represents the mean of the peak current elicited from a potential of $-60 \mathrm{mV}$ to test potentials varying from -80 to $+40 \mathrm{mV}(n=11)$. The bottom traces in $B-C$ show that the $\mathrm{Na}^{+}$currents recorded were sensitive to TTX. pacemaker and network properties within a rhythm-generating network.

\section{REFERENCES}

Al-Zubaidy ZA, Erickson RL, Greer JJ (1996) Serotonergic and noradrenergic effects on respiratory neural discharge in the medullary slice preparation of neonatal rats. Pflügers Arch 431:942-949.

Araneda R, Andrade R (1991) 5-Hydroxytryptamine-2 and 5-hydroxytryptamine-1A receptors mediate opposing responses on membrane excitability in rat association cortex. Neuroscience 40:399-412.

Arita H, Ochiishi M (1991) Opposing effects of 5-hydroxytryptamine on two types of medullary inspiratory neurons with distinct firing patterns. J Neurophysiol 66:285-292.

Astman N, Gutnick MJ, Fleidervish IA (1998) Activation of protein kinase $\mathrm{C}$ increases neuronal excitability by regulating persistent $\mathrm{Na}^{+}$ current in mouse neocortical slices. J Neurophysiol 80:1547-1551.

Bandla HP, Simakajornboon N, Graff GR, Gozal D (1999) Protein kinase $\mathrm{C}$ modulates ventilatory patterning in the developing rat. Am $\mathrm{J}$ Respir Crit Care Med 159:968-973.

Barnes NM, Sharp T (1999) A review of central 5-HT receptors and their function. Neuropharmacology 38:1083-1152.

Baxter G, Kennett G, Blaney F, Blackburn T (1995) 5-HT 2 receptor subtypes: a family re-united? Trends Pharmacol Sci 16:105-110.

Bianchi AL, Denavit-Saubie M, Champagnat J (1995) Central control of breathing in mammals: neuronal circuitry, membrane properties, and neurotransmitters. Physiol Rev 75:1-45.

Blank T, Zwart R, Nijholt I, Spiess J (1996) Serotonin 5-HT 2 receptor activation potentiates $N$-methyl-D-aspartate receptor-mediated ion currents by a protein kinase C-dependent mechanism. J Neurosci Res 45:153-160.

Bobker DH, Williams JT (1990) Ion conductances affected by 5-HT receptor subtypes in mammalian neurons. Trends Neurosci 13:169-173.

Bohmer G, Dinse HR, Fallert M, Sommer TJ (1979) Microelectrophoretic application of antagonists of putative neurotransmitters onto various types of bulbar respiratory neurons. Arch Ital Biol 117:13-22.

Bou-Flores C, Lajard AM, Monteau R, De Maeyer E, Seif I, Lanoir J, Hilaire G (2000) Abnormal phrenic motoneuron activity and morphology in neonatal monoamine oxidase A-deficient transgenic mice: possible role of a serotonin excess. J Neurosci 20:4646-4656.

Butera Jr RJ, Rinzel J, Smith JC (1999) Models of respiratory rhythm generation in the pre-Bötzinger complex. I. Bursting pacemaker neurons. J Neurophysiol 82:382-397.

Carr DB, Cooper DC, Ulrich SL, Spruston N, Surmeier DJ (2002) Serotonin receptor activation inhibits sodium current and dendritic excitability in prefrontal cortex via a protein kinase C-dependent mechanism. J Neurosci 22:6846-6855.

Cayetanot F, Gros F, Larincol N (2002) Postnatal changes in the respiratory response of the conscious rat to serotonin-2A/2C receptor activation are reflected in the developmental pattern of fos expression in the brainstem. Brain Res 942:51-57.

Champagnat J, Richter DW (1993) Second messenger-induced modulation of the excitability of respiratory neurones. NeuroReport $4: 861-863$.

Champagnat J, Denavit-Saubie M, Henry JL, Leviel V (1979) Catecholaminergic depressant effects on bulbar respiratory mechanisms. Brain Res 160:57-68.

Del Negro CA, Morgado-Valle C, Feldman JL (2002) Respiratory rhythm: an emergent network property? Neuron 34:821-830.

Di Pasquale E, Monteau R, Hilaire G (1994) Endogenous serotonin modulates the fetal respiratory rhythm: an in vitro study in the rat. Brain Res Dev Brain Res 80:222-232.

Egan C, Herrick-Davis K, Teitler M (1998) Creation of a constitutively activated state of the 5- $\mathrm{HT}_{2 \mathrm{~A}}$ receptor by site-directed mutagenesis: revelation of inverse agonist activity of antagonists. Ann NY Acad Sci 861:136-139.

Elsen FP, Ramirez JM (1998) Calcium currents of rhythmic neurons recorded in the isolated respiratory network of neonatal mice. J Neurosci 15:10652-10662.

Franceschetti S, Taverna S, Sancini G, Panzica F, Lombardi R, Avanzini G (2000) Protein kinase C-dependent modulation of $\mathrm{Na}^{+}$currents increases the excitability of rat neocortical pyramidal neurones. J Physiol (Lond) 528:291-304.

Gray PA, Janczewski WA, Mellen N, McCrimmon DR, Feldman JL (2001) Normal breathing requires pre-Bötzinger complex neurokinin-1 receptor-expressing neurons. Nat Neurosci 4:927-930.

Haji A, Pierrefiche O, Lalley PM, Richter DW (1996) Protein kinase C pathways modulate respiratory pattern generation in the cat. J Physiol (Lond) 494:297-306.

Haji A, Takeda R, Okazaki M (2000) Neuropharmacology of control of respiratory rhythm and pattern in mature mammals. Pharmacol Ther 86:277-304. 
Hwang LL, Dun NJ (1999) 5-HT modulates multiple conductances in immature rat rostral ventrolateral medulla neurones in vitro. J Physiol (Lond) 517:217-228.

Jerman JC, Brough SJ, Gager T, Wood M, Coldwell MC, Smart D, Middlemiss DN (2001) Pharmacological characterization of human 5- $\mathrm{HT}_{2}$ receptor subtypes. Eur J Pharmacol 414:23-30.

Koshiya N, Smith JC (2000) Subthreshold voltage-activated persistent sodium conductance $(\mathrm{g}(\mathrm{N} \alpha \mathrm{P}))$ in inspiratory neurons of pre-Bötzinger complex. FASEB J 14:A642.

Lalley PM, Bischoff AM, Richter DW (1994) 5-HT-1A receptormediated modulation of medullary expiratory neurones in the cat. J Physiol (Lond) 476:117-130.

Lalley PM, Bischoff AM, Schwarzacher SW, Richter DW (1995) 5-HT receptor-controlled modulation of medullary respiratory neurones in the cat. J Physiol (Lond) 487:653-661.

Lalley PM, Benacka R, Bischoff AM, Richter DW (1997) Nucleus raphe obscurus evokes 5-HT-1A receptor-mediated modulation of respiratory neurons. Brain Res 747:156-159.

Lee K, Dixon AK, Pinnock RD (1999) Serotonin depolarizes hippocampal interneurones in the rat stratum oriens by interaction with $5 \mathrm{HT}_{2}$ receptors. Neurosci Lett 270:56-58.

Lieske SP, Thoby-Brisson M, Telgkamp P, Ramirez JM (2000) Reconfiguration of the neural network controlling multiple breathing patterns: eupnea, sighs and gasps. Nat Neurosci 3:600-607.

Lindsay AD, Feldman JL (1993) Modulation of respiratory activity of neonatal rat phrenic motoneurones by serotonin. J Physiol (Lond) 461:213-233.

Marek GJ, Aghajanian GK (1996) LSD and the phenethylamine hallucinogen DOI are potent partial agonists at $5-\mathrm{HT}_{2 \mathrm{~A}}$ receptors on interneurons in rat piriform cortex. J Pharmacol Exp Ther 278:1373-1382.

Martin GR, Humphrey PP (1994) Receptors for 5-hydroxytryptamine: current perspectives on classification and nomenclature. Neuropharmacology 33:261-273.

McCrimmon DR, Ramirez JM, Alford S, Zuperku EJ (2000) Unraveling the mechanism for respiratory rhythm generation. BioEssays 22:6-9.

McCrimmon DR, Monnier A, Ptak K, Zummo G, Zhang Z, Alheid GF (2001) Respiratory rhythm generation: pre-Bötzinger neuron discharge patterns and persistent sodium current. Adv Exp Med Biol 499:147-152.

Morin D, Hennequin S, Monteau R, Hilarie G (1990) Serotonergic influences on central respiratory activity: an in vitro study in the newborn rat. Brain Res 535:281-287.

Morin D, Monteau R, Hilaire G (1991) 5-Hydroxytryptamine modulates central respiratory activity in the newborn rat: an in vitro study. Eur J Pharmacol 192:89-95.

Neher E (1992) Correction for liquid junction potentials in patch clamp experiments. Methods Enzymol 207:123-131.

Nusbaum MP, Beenhakker MP (2002) A small-systems approach to motor pattern generation. Nature 417:343-350.

Onimaru H, Shamoto A, Homma I (1998) Modulation of respiratory rhythm by 5 -HT in the brainstem-spinal cord preparation from newborn rat. Pflügers Arch 435:485-494.

Ramirez JM, Quellmalz UJ, Richter DW (1996) Postnatal changes in the mammalian respiratory network as revealed by the transverse brainstem slice of mice. J Physiol (Lond) 491:799-812.

Rauser L, Savage JE, Meltzer HY, Roth BL (2001) Inverse agonist actions of typical and atypical antipsychotic drugs at the human 5-hydroxytryptamine(2C) receptor. J Pharmacol Exp Ther 299:83-89.

Rekling JC, Feldman JL (1998) Pre-Bötzinger complex and pacemaker neurons: hypothesized site and kernel for respiratory rhythm generation. Annu Rev Physiol 60:385-405.

Richerson GB, Wang W, Tiwari J, Bradley SR (2001) Chemosensitivity of serotonergic neurons in the rostral ventral medulla. Respir Physiol 129:175-189.

Richter DW, Lalley PM, Pierrefiche O, Haji A, Bischoff AM, Wilken B, Hanefeld F (1997) Intracellular signal pathways controlling respiratory neurons. Respir Physiol 110:113-123.

Rose D, Khater-Boidin J, Toussaint P, Duron B (1995) Central effects of 5-HT on respiratory and hypoglossal activities in the adult cat. Respir Physiol 101:59-69.

Schreibmayer W (1999) Isoform diversity and modulation of sodium channels by protein kinases. Cell Physiol Biochem 9:187-200.

Sitges M, Pena F, Chiu LM, Guarneros A (1998) Study on the possible involvement of protein kinases in the modulation of brain presynaptic sodium channels: comparison with calcium channels. Neurochem Int 32:177-190.

Smith JC, Ellenberger HH, Ballanyi K, Richter DW, Feldman JL (1991) Pre-Bötzinger complex: a brainstem region that may generate respiratory rhythm in mammals. Science 254:726-729.

Smith JC, Butera RJ, Koshiya N, Del Negro C, Wilson CG, Johnson SM (2000) Respiratory rhythm generation in neonatal and adult mammals: the hybrid pacemaker-network model. Respir Physiol 122:131-147.

Telgkamp P, Ramirez JM (1999) Differential responses of respiratory nuclei to anoxia in rhythmic brain stem slices of mice. J Neurophysiol 82:2163-2170.

Telgkamp P, Cao YQ, Basbaum AI, Ramirez JM (2002) Long-term deprivation of substance $\mathrm{P}$ in PPT-A mutant mice alters the anoxic response of the isolated respiratory network. J Neurophysiol $88: 206-213$.

Thoby-Brisson M, Ramirez JM (2001) Identification of two types of inspiratory pacemaker neurons in the isolated respiratory neural network of mice. J Neurophysiol 86:104-112.

Thoby-Brisson M, Telgkamp P, Ramirez JM (2000) The role of the hyperpolarization-activated current in modulating rhythmic activity in the isolated respiratory network of mice. J Neurosci 20:2994-3005.

Walaas SI, Greengard P (1991) Protein phosphorylation and neuronal function. Pharmacol Rev 43:299-349.

Wang HY, Friedman E (1990) Central 5-hydroxytryptamine receptorlinked protein kinase $\mathrm{C}$ translocation: a functional postsynaptic signal transduction system. Mol Pharmacol 37:75-79. 